\title{
Perfil de sensibilidade de células sésseis e planctônicas de Escherichia coli a antimicrobianos usados no tratamento da mastite bovina
}

\author{
[Sensitivity profile of planktonic and sessile cells of Escherichia coli to antimicrobial used in the \\ treatment of bovine mastitis]
}

J.C.M. Costa, I.F. Espeschit, F.A. Pieri, I.A. Carvalho, M.A.S. Moreira*

Universidade Federal de Viçosa - UFV - Viçosa, MG

\begin{abstract}
RESUMO
Escherichia coli é um micro-organismo altamente adaptativo e sua habilidade em formar biofilmes pode ser fundamental na resistência a tratamentos com antimicrobianos. A avaliação da concentração mínima inibitória (CMI) vem sendo utilizada para verificar a sensibilidade dos micro-organismos aos antimicrobianos. Entretanto, quando se avaliam células sésseis, a concentração do antimicrobiano requerido para erradicação do biofilme é maior do que a determinada pela CMI. Objetivou-se comparar as CMI com as concentrações mínimas de erradicação de biofilmes (CMEB) de antimicrobianos usados no tratamento da mastite em 27 isolados de E. coli produtores de biofilmes provenientes de mastite. Os isolados foram submetidos a testes de sensibilidade a antimicrobianos usados no tratamento da mastite, tanto para células planctônicas, por meio da CMI, quanto para células sésseis, pela avaliação da CMEB. Os resultados revelaram uma alta sensibilidade: apenas quatro $(14,8 \%)$ isolados obtiveram valores da CMI elevados, variando de 4 a $10 \mu \mathrm{g} / \mathrm{mL}$, sendo classificados como resistentes. Para os demais isolados $(85,2 \%)$, os valores foram menores, variando de 0,125 a $2 \mu \mathrm{g} / \mathrm{mL}$, classificados como sensíveis. A avaliação de CMEB indicou que a concentração dos antimicrobianos necessária para eliminar as células sésseis variou de $100 \mu \mathrm{g} / \mathrm{mL}$ a $500 \mu \mathrm{g} / \mathrm{mL}$. Os valores de CMEB foram significativamente maiores nos isolados grandes e moderados produtores de biofilmes em relação aos isolados fracos produtores de biofilmes $(p<0,001)$. Não houve correlação entre os valores de CMEB e CMI ( $>00,05)$. A escolha da terapêutica antimicrobiana correta para o tratamento de infecções intramamárias em bovinos relacionadas com a produção de biofilmes parece exigir a aplicação de testes mais específicos. Testes de susceptibilidade antimicrobiana baseados apenas em valores de CMI mostraram-se ineficazes em determinar com precisão a susceptibilidade das células bacterianas sésseis.
\end{abstract}

Palavras-chaves: bovino, leite, resistência, bactéria Gram negativa,

\begin{abstract}
Escherichia coli is a highly adaptive microorganism. Its ability to form biofilms may be critical for resistance to antimicrobial treatments. Evaluation of minimum inhibitory concentration (MIC) has been used to check the sensitivity of microorganisms to antibiotics, however, when evaluating sessile cells, the required antibiotic concentration to eradicate biofilm is greater than determined by MIC. This study aimed to compare MIC with minimum biofilm eradication concentration (MBEC) of antimicrobials used in mastitis treatment in $27 \mathrm{E}$. coli biofilm producers isolates from mastitis. Isolates were tested for sensitivity to antimicrobials used in mastitis treatment, for both planktonic cells (by CMI) and sessile cells (by MBEC). The results revealed high sensitivity: only four (14.8\%) isolates showed high MIC values, ranging from 4 to $10 \mathrm{~g} / \mathrm{mL}$ and they were classified as resistant. All other isolates (85.2\%) showed lower values, ranging from 0.125 to $2 \mathrm{mg} / \mathrm{mL}$, and they were classified as sensitive. Evaluation of MBEC indicated that concentration of antimicrobial needed to remove sessile cells ranged from $100 \mathrm{mg} / \mathrm{mL}$ to $500 \mathrm{mg} / \mathrm{mL}$. MBEC values were significantly higher in large and moderate biofilm producers isolates
\end{abstract}

Recebido em 16 de setembro de 2012

Aceito em 17 de julho de 2013

*Autor para correspondência (corresponding author)

E-mail:masm@ufv.br 
regarding weak biofilm producers isolates ( $p<0.001$ ). There was no correlation between MBEC and CMI values $(p>0.05)$. The correct choice of antimicrobial therapy for treatment of mammary infections in cattle related to biofilm production seems to require application of more specific tests. Antimicrobial susceptibility testing based only on MIC values proved ineffectiveness to accurately determination the susceptibility of sessile bacterial cells.

Keywords: cattle, milk, resistance, Gram negative bacterium

\section{INTRODUÇÃO}

Biofilme é uma comunidade estruturada de micro-organismos organizados dentro de um complexo de estruturas e aderidos a uma superfície viva ou inerte (Costerton et al., 1999). Representa provavelmente um dos mais importantes mecanismos de colonização e fixação pelos micro-organismos na natureza (Costerton et al., 1999; Flint et al., 2011). Embora os estudos sobre os micro-organismos produtores de biofilmes na área médicaveterinária ainda sejam escassos, sabe-se que há uma possível influência desses agentes no estabelecimento, controle e tratamento das diversas infecções que acometem os animais, notadamente nas infecções da glândula mamária, mastite, dos bovinos (Melchior et al., 2006).

As mastites causadas por Escherichia coli ocorrem geralmente durante o período seco e logo após o parto; são geralmente transitórias e associadas a quadros clínicos agudos ou superagudos, que podem levar à morte do animal (Burvenich et al., 2003; Hogan and Larry Smith, 2003; Bansal et al., 2005). Entretanto, alguns isolados de $E$. coli possuem uma maior habilidade em replicar no tecido mamário e em aderir a este, podendo determinar infecções persistentes no hospedeiro (Dogan et al., 2006; Fontaine e Smith, 2006). Esse fato é um problema de maior relevância em rebanhos com baixa prevalência de patógenos contagiosos e em vacas com contagem de células somáticas (CCS) menor que 150.000 células/mL (Bradley e Green, 2001; Oliver et al., 2011).

Antibioticoterapia é o tratamento de escolha para esse tipo de mastite. Assim, os testes utilizados para verificar a sensibilidade a antimicrobianos dos micro-organismos se baseiam no antibiograma pela técnica de difusão de discos e na avaliação da concentração mínima inibitória (CMI) (Steeneveld et al., 2011). Este último, por gerar resultados mais confiáveis e precisos, vem sendo o mais utilizado atualmente. Porém, quando se avalia células sésseis, organizadas em biofilmes, esses métodos não fornecem resultados precisos, pois ensaios de sensibilidade efetuados nessas células mostram que a concentração do antimicrobiano requerido para erradicação do biofilme é muitas vezes maior do que a determinada na CMI (Hoiby et al., 2010).

Estudos in vitro demonstram que células bacterianas organizadas em biofilmes, sésseis, tornaram-se 10 a 1.000 vezes mais resistentes aos efeitos dos agentes antimicrobianos quando comparadas com as células planctônicas dos mesmos isolados (Hoiby et al., 2010; Shafahi e Vafai, 2010; Antunes et al., 2011). A terapia padrão com antimicrobianos é somente capaz de eliminar células planctônicas, deixando as formas sésseis vivas para propagação quando terminar o tratamento (Schwarz et al., 2011). Esse fato pode explicar o reaparecimento da sintomatologia da mastite mesmo após o tratamento com antimicrobianos, o que é embasado por estudos epidemiológicos que sugerem que mais de $40 \%$ dos casos de mastite foram recorrentes após o fim do tratamento (Hillerton e Berry, 2005). Lipman et al. (1995) observaram a recidiva da mastite nos mesmos quartos e causada pela mesma cepa de E. coli, após antibioticoterapia, o que não deveria ser comum, pela grande diversidade de cepas de $E$. coli distribuídas no ambiente; logo, a reinfecção com a mesma cepa sugere a sobrevivência do micro-organismo no hospedeiro, resultado de uma infecção intramamária persistente (Passey et al., 2008).

Além disso, há evidências de que determinados antimicrobianos podem estimular a produção de biofilmes pelos micro-organismos (Bradley e Green, 2001; Melchior et al., 2006; Costa et al., 2012), inclusive os usados na terapia da mastite, como a seguir. Três classes de antimicrobianos, incluindo tetraciclinas, quinopristina-dalfopristina e eritromicina, estimulam a expressão de genes ica envolvidos na produção de biofilmes por Staphylococcus epidermidis (Melchior et al., 
2006; Oliveira et al., 2007). Chen et al. (2010) observaram indução dos genes acrA, agn43, $\operatorname{csg} A, \quad \operatorname{csg} D, \quad o m p F$ e pgaA, envolvidos na resistência a antimicrobianos e na produção de biofilmes, em isolados de $E$. coli sob diferentes concentrações de aminoglicosídeos. Costa et al. (2012), trabalhando com E. coli, verificaram que a enrofloxacina, uma quinolona, foi capaz de induzir a produção de biofilmes em concentração subinibitória.

Desse modo, o conhecimento do perfil de sensibilidade de células sésseis é fundamental para se estabelecerem estratégias de tratamentos eficientes, diminuindo assim falhas na terapia e recidivas da doença. Este trabalho objetivou comparar as concentrações mínimas inibitórias (CMI) com as concentrações mínimas de erradicação de biofilmes (CMEB) de antimicrobianos usados no tratamento da mastite em isolados produtores de biofilmes de E. coli provenientes de mastite.

\section{MATERIAL E MÉTODOS}

Foram utilizados 27 isolados de E. coli produtores de biofilmes provenientes de amostras de leite de animais com mastite clínica, sendo cinco classificados como grandes produtores de biofilmes (GPB), 11 como moderados produtores de biofilmes (MPB) e 11 como fracos produtores de biofilmes (FPB) (Fernandes et al., 2011). Todos os isolados foram armazenados em caldo Infusão de Cérebro e Coração (BHI, Oxoid, Cambridge, Inglaterra) acrescidos de $20 \%$ de glicerol e estocados a $-80^{\circ} \mathrm{C}$. Antes da utilização, cada isolado foi estriado em placas de Petri contendo ágar MacConkey (Oxoid, Cambridge, Inglaterra) e incubados à temperatura de $37^{\circ} \mathrm{C}$ por 24 horas.

Previamente foram preparadas soluções estoques, na concentração de $1.000 \mathrm{mg} / \mathrm{mL}$, dos seguintes antimicrobianos utilizados no tratamento da mastite ambiental: ampicilina, cefalexina, ceftiofur, cotrimoxazol, enrofloxacina e gentamicina. Essas soluções foram novamente diluídas, seriadamente, em água destilada para as diferentes concentrações utilizadas, filtradas em membrana com poro de $0,22 \mu \mathrm{m}$ de diâmetro (Schleicher e Schuel, Alemanha), aliquotadas e armazenadas à temperatura de $-20^{\circ} \mathrm{C}$ até o momento das análises, respeitados os períodos de viabilidade do antimicrobiano.
Os isolados foram submetidos ao teste de sensibilidade aos antimicrobianos para a obtenção da CMI conforme Moreira et al. (2005). Para isso, $230 \mu \mathrm{L}$ de cultura de cada isolado, diluídos a $1,0 \times 10^{5} \mathrm{UFC} / \mathrm{mL}$, foram adicionados aos orifícios de placas de microtitulação (Nunc-Iimmuno plates, Dinamarca), juntamente com $70 \mu \mathrm{L}$ das soluções dos antimicrobianos, em diferentes concentrações. O caldo BHI (Oxoid, Cambridge, Inglaterra), no volume de $230 \mu \mathrm{L}$ acrescido de $70 \mu \mathrm{L}$ das soluções antimicrobianas nas diferentes concentrações, foi usado como controle negativo. Para o controle positivo, utilizaram-se $230 \mu \mathrm{L}$ das culturas diluídas juntamente com $70 \mu \mathrm{L}$ de água destilada. O crescimento dos isolados foi acompanhado em um aparelho leitor de absorbância em microplacas (Titertek multiskan ${ }^{\circledR}$, Plus-MKII), e as leituras das D.O.550 foram feitas em intervalos de tempo preestabelecidos até a estabilização dos valores. A curva de crescimento foi construída com a média estabelecida das triplicatas e plotada em programa Excel 2007 (Microsoft Corporation, Redmond, Estados Unidos). A CMI foi definida como a menor concentração do antimicrobiano que irá impedir o crescimento bacteriano até duas horas após o tempo correspondente ao início da fase estacionária do controle positivo. Todos os procedimentos foram realizados em triplicata.

Para obtenção da CMEB, utilizou-se a metodologia de Lucchesi et al. (2012) com modificações. Para isso, tubos de ensaio foram preenchidos com cinco esferas de vidro com 2,00 $\mathrm{mm}$ de diâmetro, juntamente com $5,0 \mathrm{~mL}$ de cultura de cada um dos 27 isolados em caldo BHI a $1,0 \times 10^{8} \mathrm{UFC} / \mathrm{mL}$ e incubados por 24 horas à temperatura de $37^{\circ} \mathrm{C}$. Após a incubação, as esferas foram removidas com auxílio de uma pinça, transferidas para novos tubos de ensaio e lavadas três vezes com solução salina. Após as lavagens, os tubos foram preenchidos com $5,0 \mathrm{~mL}$ de caldo BHI juntamente com os antimicrobianos a concentrações de 100, 200, 300,400 e $500 \mu \mathrm{g} / \mathrm{mL}$ e incubados por 24 horas a $37^{\circ} \mathrm{C}$. Posteriormente, as esferas foram lavadas com solução salina e transferidas para novos tubos contendo $5,0 \mathrm{~mL}$ de caldo BHI. Os tubos foram submetidos à agitação por 9 minutos a $2.000 \mathrm{rpm}$ e incubados por 24 horas à 
temperatura de $37^{\circ} \mathrm{C}$, momento em que foi avaliado o crescimento celular por turbidez e plaqueamento de alíquota da cultura em ágar MacConkey. A menor concentração na qual não se verificou crescimento bacteriano foi denominada como concentração mínima de erradicação do biofilme (CMEB).

Visando obter a concentração de células sésseis desagregadas da superfície das esferas e confirmar a ação das CMEB sobre os biofilmes, seis isolados foram escolhidos aleatoriamente. Para isso, as esferas de cada isolado foram submetidas à respectiva CMEB de um antimicrobiano. Como controle positivo, as esferas foram submetidas a caldo BHI sem antimicrobianos. A metodologia seguiu-se conforme descrito anteriormente e, após a agitação a $2.000 \times \mathrm{g}$, alíquotas de $1,0 \mathrm{~mL}$ de cada um dos tubos foram retiradas, diluídas seriadamente e plaqueadas em placas com ágar MacConkey. As placas foram incubadas a $37^{\circ} \mathrm{C}$ por 24 horas, e as unidades formadoras de colônias (UFC) foram quantificadas nas placas contendo 25 a 250 colônias.

Para avaliar se os dados obtidos no trabalho seguem a distribuição normal, empregou-se o teste de normalidade de Anderson-Darling. O teste de Kruskal-Wallis foi utilizado para identificar possíveis diferenças entre aos valores de CMEB das distintas categorias de isolados (grande, moderado e fraco produtor de biofilme), posteriormente empregou-se o teste de Dunn's para localizar as diferenças entre as categorias. $\mathrm{O}$ teste de correlação de Spearman foi usado para avaliar a possível correlação entre os valores de CMI e CMEB. Os testes foram realizados em três repetições, e o nível de significância adotado foi de $5 \%(\alpha=0,05)$. Para a realização dos referidos testes estatísticos, empregou-se o software Minitab 15®.

\section{RESULTADOS E DISCUSSÃO}

Foram observados valores de CMI variando entre $0,125 \mu \mathrm{g} / \mathrm{mL}$ a $10 \mu \mathrm{g} / \mathrm{mL}$ para os 27 isolados analisados. Os maiores valores foram obtidos para quatro isolados, que obtiveram, para o cotrimoxazol, CMI de $10 \mu \mathrm{g} / \mathrm{mL}(4 / 4)$ e, para

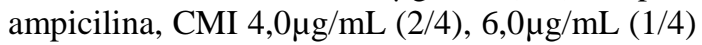
e $8,0 \mu \mathrm{g} / \mathrm{mL}$ (1/4) (Tab. 1). Entretanto, para o restante dos isolados, $23 / 27(85,2 \%)$ no total, os valores de CMI obtidos foram baixos, variando de 0,125 a $0,25 \mu \mathrm{g} / \mathrm{mL}$ para ampicilina, 0,5 a $1,0 \mu \mathrm{g} / \mathrm{mL}$ para ceftiofur, 1,0 a $2,0 \mu \mathrm{g} / \mathrm{mL}$ para cefalexina, 0,125 a $0,25 \mu \mathrm{g} / \mathrm{mL}$ para enrofloxacina, 0,5 a $2,0 \mu \mathrm{g} / \mathrm{mL}$ para cotrimoxazol e 0,5 a $2,0 \mu \mathrm{g} / \mathrm{mL}$ para gentamicina (Tab. 1 ).

Tabela 1. Distribuição em porcentagem das concentrações mínimas inibitórias (CMI) e perfis de resistência dos isolados de Escherichia coli $(\mathrm{n}=27)$ provenientes de mastite

\begin{tabular}{lcccccccccc}
\hline \multicolumn{1}{c}{ Distribuição $(\%)$ das CMI $(\mu \mathrm{g} / \mathrm{mL})$} \\
\hline Antimicrobiano & $\mathrm{R}(\%)$ & 0,125 & 0,25 & 0,5 & 1 & 2 & 4 & 6 & 8 & 10 \\
\hline AMP & 14,81 & 40,74 & 44,45 & & & & 7,41 & 3,7 & 3,7 \\
CTF & 0 & & & 40,74 & 59,26 & & & & \\
CEF & 0 & & & & 62,9 & 37,1 & & & \\
ENO & 0 & 6 & 74 & & & & & & \\
GEN & 0 & & & 7,41 & 88,9 & 3,69 & & & \\
SUT & 14,81 & & & 37,1 & 37,1 & 10,99 & & & & 14,81 \\
\hline
\end{tabular}

R: resistência; AMP: ampicilina; CTF: ceftiofur; CEF: cefalexina; ENO: enrofloxacina; GEN: gentamicina; SUT: cotrimoxazol.

Resultados semelhantes foram obtidos na Suécia por Bengtsson et al. (2009) que, avaliando a resistência de 743 isolados bacterianos causadores de mastite clínica, encontraram um perfil de alta sensibilidade para E. coli, S. uberis, $S$. dysgalactiae e $S$. agalactiae à maioria dos antimicrobianos usados. No mesmo estudo, destaca-se que as CMI encontradas para E. coli se assemelharam aos encontrados no presente trabalho, com $100 \%$ desses valores entre $0,25 \mu \mathrm{g} / \mathrm{mL}$ e $1,0 \mu \mathrm{g} / \mathrm{mL}$ para ceftiofur, $74,8 \%$ entre $0,5 \mu \mathrm{g} / \mathrm{mL}$ e $2,0 \mu \mathrm{g} / \mathrm{mL}$ para ampicilina, $92 \%$ entre $0,5 \mu \mathrm{g} / \mathrm{mL}$ e $2,0 \mu \mathrm{g} / \mathrm{mL}$ para gentamicina e $100 \%$ entre $0,03 \mu \mathrm{g} / \mathrm{mL}$ e $0,12 \mu \mathrm{g} / \mathrm{mL}$ para enrofloxacina.

Em princípio, a alta taxa de sensibilidade encontrada por Bengtsson et al. (2009) e pelo 
presente trabalho se mostra favorável ao emprego de antimicrobianos no tratamento da mastite causada por esses isolados de E. coli. Todavia, estudos vêm demonstrando que o sucesso da terapia antimicrobiana da mastite tem sido muitas vezes ineficaz, resultando em infecções persistentes e/ou recidivantes após o tratamento (Dogan et al., 2006; Melchior et al., 2006). Uma das hipóteses para explicar essa resistência à terapia é a habilidade dos isolados de E. coli, assim como outros micro-organismos, de se aderirem à superfície do tecido da glândula mamária infectada e aí se multiplicarem e formarem biofilmes, desenvolvendo desse modo uma resistência inata à maioria dos agentes antimicrobianos (Melchior et al., 2006). Esse fato pode ser confirmado em razão de os testes de CMI avaliarem apenas o perfil de sensibilidade das células planctônicas, não permitindo extrapolar seus resultados para as células sésseis, mais resistentes à ação dos antimicrobianos.

O resultado obtido demonstrou alta resistência das células sésseis de E. coli aos antimicrobianos em relação às planctônicas, sendo esse fato confirmado pelos valores de CMEB terem sido superiores aos valores de CMI correspondentes (Tab. 2-7).

De acordo com a literatura, bactérias organizadas em biofilmes tornam-se de 10 a 1.000 vezes mais resistentes à ação de antimicrobianos em relação às bactérias livres (Hoiby et al., 2010). Entretanto, para o presente estudo, células sésseis dos isolados GPB e MPB foram até 2.500 vezes mais resistentes à ampicilina (dois isolados GPB e dois MPB) e até 2.400 à enrofloxacina (dois isolados GPB e dois MPB) (Tab. 2 e 6). Para as células sésseis dos isolados FPB, esse aumento de resistência foi menor, variando de 333,4 para ampicilina (três isolados) a quatro para cotrimoxazol (dois isolados) (Tab. 2 e 5). Da mesma forma, foi possível observar também que, para os isolados classificados como resistentes, o aumento da resistência foi menor comparado aos isolados sensíveis, variando de quatro para ampicilina (dois isolados FPB) a 25 (dois isolados FPB). Esses resultados indicam uma maior eficácia dos antimicrobianos sob os isolados FPB de E. coli, usados no experimento, quando comparados aos resultados dos isolados GPB e MPB.

Tabela 2. Comparação entre as concentrações mínimas inibitórias (CMI) e as concentrações mínimas de erradicação de biofilmes (CMEB) de ampicilina para isolados produtores de biofilmes de Escherichia coli provenientes de mastite

\begin{tabular}{ccccc}
\hline $\begin{array}{c}\text { Isolados } \\
\mathrm{n}=27\end{array}$ & Categ. & $\begin{array}{c}\text { CMI } \\
(\mu \mathrm{g} / \mathrm{mL})\end{array}$ & $\begin{array}{c}\text { CMEB } \\
(\mu \mathrm{g} / \mathrm{mL})\end{array}$ & Razão* \\
\hline 1 & GPB & 0,12 & 200,0 & 1667,0 \\
2 & GPB & 0,12 & 300,0 & 2500,0 \\
1 & GPB & 0,25 & 200,0 & 800,0 \\
1 & GPB & 0,25 & 300,0 & 1200,0 \\
4 & MPB & 0,12 & 200,0 & 1667,0 \\
2 & MPB & 0,12 & 300,0 & 2500,0 \\
2 & MPB & 0,25 & 200,0 & 800,0 \\
1 & MPB & 0,25 & 300,0 & 1200,0 \\
1 & MPB & 0,25 & 400,0 & 1600,0 \\
1 & MPB & 0,25 & 500,0 & 2000,0 \\
3 & FPB & 0,12 & 40,0 & 333,4 \\
3 & FPB & 0,25 & 40,0 & 160,0 \\
1 & FPB & 0,25 & 40,0 & 160,0 \\
2 & FPB & 4,0 & 100,0 & 25,0 \\
1 & FPB & 6,0 & 60,0 & 10,0 \\
1 & FPB & 8,0 & 100,0 & 12,5 \\
\hline
\end{tabular}

Categ: Categoria; GPB: grande produtor de biofilmes; MPB: moderado produtor de biofilmes; FPB: fraco produtor de biofilmes. *Razão $=\mathrm{CMEB} / \mathrm{CMI}$.

Tabela 3. Comparação entre as concentrações mínimas inibitórias (CMI) e as concentrações mínimas de erradicação de biofilmes (CMEB) de ceftiofur para isolados produtores de biofilmes de Escherichia coli provenientes de mastite

\begin{tabular}{ccccc}
\hline $\begin{array}{c}\text { Isolados } \\
\mathrm{n}=27\end{array}$ & Categ. & $\begin{array}{c}\text { CMI } \\
(\mu \mathrm{g} / \mathrm{mL})\end{array}$ & $\begin{array}{c}\text { CMEB } \\
(\mu \mathrm{g} / \mathrm{mL})\end{array}$ & Razão* \\
\hline 2 & GPB & 1,0 & 300,0 & 300,0 \\
3 & GPB & 1,0 & 400,0 & 400,0 \\
5 & MPB & 1,0 & 300,0 & 300,0 \\
2 & MPB & 1,0 & 400,0 & 400,0 \\
4 & MPB & 2,0 & 400,0 & 200,0 \\
5 & FPB & 1,0 & 40,0 & 40,0 \\
6 & FPB & 2,0 & 40,0 & 20,0
\end{tabular}

Categ.: Categoria; GPB: grande produtor de biofilmes; MPB: moderado produtor; FPB: fraco produtor. $*$ Razão = CMEB/CMI. 
Tabela 4. Comparação entre as concentrações mínimas inibitórias (CMI) e as concentrações mínimas de erradicação de biofilmes (CMEB) de cefalexina para isolados produtores de biofilmes de Escherichia coli provenientes de mastite

\begin{tabular}{ccccc}
$\begin{array}{c}\text { Isolados } \\
\mathrm{n}=27\end{array}$ & Categ. & $\begin{array}{c}\text { CMI } \\
(\mu \mathrm{g} / \mathrm{mL})\end{array}$ & $\begin{array}{c}\text { CMEB } \\
(\mu \mathrm{g} / \mathrm{mL})\end{array}$ & Razão* \\
\hline 2 & GPB & 1,0 & 300,0 & 300,0 \\
3 & GPB & 1,0 & 400,0 & 400,0 \\
5 & MPB & 1,0 & 300,0 & 300,0 \\
2 & MPB & 1,0 & 400,0 & 400,0 \\
4 & MPB & 2,0 & 400,0 & 200,0 \\
5 & FPB & 1,0 & 40,0 & 40,0 \\
6 & FPB & 2,0 & 40,0 & 20,0 \\
\hline
\end{tabular}

Categ.: Categoria; GPB: grande produtor de biofilmes; MPB: moderado produtor de biofilmes; FPB: fraco produtor de biofilmes. $*$ Razão $=$ CMEB/CMI

Tabela 5. Comparação entre as concentrações mínimas inibitórias (CMI) e as concentrações mínimas de erradicação de biofilmes (CMEB) de cotrimoxazol para isolados produtores de biofilmes de Escherichia coli provenientes de mastite

\begin{tabular}{ccccc}
\hline $\begin{array}{c}\text { Isolados } \\
\mathrm{n}=27\end{array}$ & Categ. & $\begin{array}{c}\mathrm{CMI} \\
(\mu \mathrm{g} / \mathrm{mL})\end{array}$ & $\begin{array}{c}\text { CMEB } \\
(\mu \mathrm{g} / \mathrm{mL})\end{array}$ & Razão* \\
\hline 3 & GPB & 0,5 & 400,0 & 800,0 \\
2 & GPB & 2,0 & 400,0 & 200,0 \\
3 & MPB & 0,5 & 400,0 & 800,0 \\
5 & MPB & 1,0 & 400,0 & 400,0 \\
1 & MPB & 2,0 & 500,0 & 250,0 \\
2 & MPB & 10,0 & 50,0 & 5,0 \\
4 & FPB & 0,5 & 40,0 & 80,0 \\
5 & FPB & 1,0 & 40,0 & 40,0 \\
2 & FPB & 10,0 & 40,0 & 4,0 \\
\hline
\end{tabular}

Categ.: Categoria; GPB: grande produtor de biofilmes; MPB: moderado produtor de biofilmes; FPB: fraco produtor de biofilmes. *Razão $=$ CMEB/CMI.

Analisando estatisticamente as razões CMEB/CMI obtidas entre as diferentes categorias de isolados (GPB, MPB E FPB), foi possível demonstrar que a CMEB foi significativamente maior nos isolados GPB e MPB em relação aos isolados FPB ( $p<0,001)$. No entanto, quando se comparou o CMEB de isolados GPB com o de isolados MPB, as diferenças não foram significantes $(p>0,05)$ (Tab. 3-8). Esses resultados podem ser explicados pela menor difusão dos antimicrobianos pelas camadas dos biofilmes produzidos por isolados GPB e MPB, que tendem a ter uma maior biomassa e são consequentemente mais densas comparadas às camadas dos biofilmes produzidos por isolados FPB (Melchior et al., 2006). Isso poderia promover uma maior resistência das células sésseis devido à não exposição ou à exposição gradual de concentrações muito baixas do antimicrobiano (Clutterbuck et al., 2007; Hoiby et al., 2010). Não houve correlação entre os valores de CMEB e CMI com $\mathrm{p}>0,05$.

Tabela 6. Comparação entre as concentrações mínimas inibitórias (CMI) e as concentrações mínimas de erradicação de biofilmes (CMEB) de enrofloxacina para isolados produtores de biofilmes de Escherichia coli provenientes de mastite

\begin{tabular}{ccccc}
$\begin{array}{c}\text { Isolados } \\
\mathrm{n}=27\end{array}$ & Categ. & $\begin{array}{c}\text { CMI } \\
(\mu \mathrm{g} / \mathrm{mL})\end{array}$ & $\begin{array}{c}\text { CMEB } \\
(\mu \mathrm{g} / \mathrm{mL})\end{array}$ & Razão* \\
\hline 3 & GPB & 0,20 & 300,0 & 1500,0 \\
2 & GPB & 0,125 & 300,0 & 2400,0 \\
4 & MPB & 0,20 & 200,0 & 1000,0 \\
5 & MPB & 0,20 & 300,0 & 1500,0 \\
2 & MPB & 0,125 & 300,0 & 2400,0 \\
8 & FPB & 0,20 & 20,0 & 100,0 \\
3 & FPB & 0,125 & 40,0 & 320,0 \\
\hline
\end{tabular}

Categ.: Categoria; GPB: grande produtor de biofilmes; MPB: moderado produtor de biofilmes; FPB: fraco produtor de biofilmes. *Razão $=\mathrm{CMEB} / \mathrm{CMI}$.

Tabela 7. Comparação entre as concentrações mínimas inibitórias (CMI) e as concentrações mínimas de erradicação de biofilmes (CMEB) de gentamicina para isolados produtores de biofilmes de Escherichia coli provenientes de mastite

\begin{tabular}{cccrr}
$\begin{array}{c}\text { Isolados } \\
\mathrm{n}=27\end{array}$ & Categ. & $\begin{array}{c}\mathrm{CMI} \\
(\mu \mathrm{g} / \mathrm{mL})\end{array}$ & $\begin{array}{c}\text { CMEB } \\
(\mu \mathrm{g} / \mathrm{mL})\end{array}$ & Razão* \\
\hline 3 & GPB & 1,0 & 300,0 & 300,0 \\
1 & GPB & 1,0 & 400,0 & 400,0 \\
1 & GPB & 1,0 & 500,0 & 500,0 \\
5 & MPB & 1,0 & 300,0 & 300,0 \\
4 & MPB & 1,0 & 400,0 & 400,0 \\
1 & MPB & 1,0 & 500,0 & 500,0 \\
1 & MPB & 2,0 & 500,0 & 250,0 \\
2 & FPB & 0,5 & 60,0 & 120,0 \\
3 & FPB & 1,0 & 80,0 & 80,0 \\
2 & FPB & 1,0 & 60,0 & 60,0 \\
4 & FPB & 1,0 & 40,0 & 40,0 \\
\hline
\end{tabular}

Categ.: Categoria; GPB: grande produtor de biofilmes; MPB: moderado produtor de biofilmes; FPB: fraco produtor de biofilmes. $*$ Razão $=$ CMEB/CMI. 
Tabela 8. Taxa de recuperação celular média de células sésseis de sete isolados produtores de biofilmes de Escherichia coli provenientes de mastite desagregadas das esferas de vidro submetidas às respectivas concentrações mínimas de erradicação de biofilmes (CMEB) em cada antimicrobiano testado

\begin{tabular}{cccc}
$\begin{array}{c}\text { Isolados } \\
\mathrm{n}=7\end{array}$ & $\begin{array}{c}\text { Antimi- } \\
\text { crobiano }\end{array}$ & $\begin{array}{c}\text { CMEB } \\
(\mu \mathrm{g} / \mathrm{mL})\end{array}$ & $\begin{array}{c}\text { Concentração } \\
(\mathrm{UFC} / \mathrm{mL})\end{array}$ \\
\hline 1 & AMP & 200 & 0 \\
1 & CTF & 400 & 0 \\
1 & CEF & 300 & 0 \\
1 & ENO & 400 & 0 \\
1 & GEN & 300 & 0 \\
1 & SUT & 400 & 0 \\
\hline 7 & S/ATB & 0 & $1,96 \times 10^{6}$ \\
\hline
\end{tabular}

AMP: ampicilina; CTF: ceftiofur; CEF: cefalexina; ENO: enrofloxacina; GEN: gentamicina; SUT: cotrimoxazol; S/ATB: sem antimicrobianos.

Resultados semelhantes foram encontrados por Antunes et al. (2011), que demonstraram maiores valores de CMEB de vancomicina para isolados de Staphylococcus spp, GPB e MPB, obtidos de cateteres, quando comparados aos FPB. Esse aumento, assim como no presente trabalho, não foi verificado quando compararam as CMEB dos isolados GPB com MPB, e não foi encontrada correlação entre os valores de CMEB e CMI. Em seus resultados, entretanto, os valores de CMEB foram inferiores aos encontrados neste trabalho.

A escolha da terapêutica antimicrobiana correta para o tratamento de infecções intramamárias em bovinos relacionadas com a produção de biofilmes parece exigir a aplicação de testes mais específicos. Apenas testes de susceptibilidade antimicrobiana baseados em valores de CMI têm se mostrado ineficazes em determinar com precisão a susceptibilidade das células bacterianas sésseis.

\section{CONCLUSÕES}

As CMI dos antimicrobianos testados, frequentemente usadas para o tratamento clínico da mastite, não foram eficientes na eliminação das células sésseis de E. coli, sendo requeridas concentrações muito superiores àquelas indicadas e praticadas nas terapias. Nenhuma colônia foi visualizada a partir das esferas submetidas às $\mathrm{CMEB}$; contudo, concentrações médias de 1,96 x $10^{6} \mathrm{UFC} / \mathrm{mL}$ foram obtidas nas esferas não submetidas à ação dos antimicrobianos, demonstrando a efetividade das CMEB sobre as células sésseis de E. coli.

\section{AGRADECIMENTOS}

À Fundação de Amparo à Pesquisa de Minas Gerais (FAPEMIG), ao Conselho Nacional de Desenvolvimento Científico e Tecnológico (CNPq) e à Coordenação de aperfeiçoamento de Pessoal de Nível Superior (CAPES) pelo suporte financeiro.

\section{REFERÊNCIAS}

ANTUNES, A.L.S.; BONFANTI, J.W.; PEREZ, L.R.R. et al. High vancomycin resistance among biofilms produced by Staphylococcus species isolated from central venous catheters. Mem. Inst. Oswaldo Cruz, v.106, p.51-55, 2011.

BANSAL, B.K.; HAMANN, J.; GRABOWSKIT, N.T.; SINGH, K.B. Variation in the composition of selected milk fraction samples from healthy and mastitic quarters, and its significance for mastitis diagnosis. J. Dairy Res., v.72, p.144-152, 2005.

BENGTSSON, B.; UNNERSTAD, H.E.; EKMAN, T. et al. Antimicrobial susceptibility of udder pathogens from cases of acute clinical mastitis in dairy cows. Vet. Microbiol., v.136, p.142-149, 2009.

BRADLEY, A.J.; GREEN, M.J. Adaptation of Escherichia coli to the bovine mammary gland. J. Clin. Microbiol., v.39, p.1845-1849, 2001.

BURVENICH, C.; VAN MERRIS, V.; MEHRZAD, J. et al. Severity of E. coli mastitis is mainly determined by cow factors. Vet. Res., v.34, p.521-64, 2003.

CHEN, C.; LIAO, X.; JIANG, H. et al. Characteristics of Escherichia coli biofilm production, genetic typing, drug resistance pattern and gene expression under aminoglycoside pressures. Environ. Toxicol. Pharmacol., v.30, p.5-10, 2010.

CLUTTERBUCK, A.L.; WOODS, E.J.; KNOTTENBELT, D.C. et al. Biofilms and their relevance to veterinary medicine. Vet. Microbiol., v.121, p.1-17, 2007. 
COSTA, J.C.; ESPESCHIT, I.F.; PIERI, F.A. et al. Increased production of biofilms by Escherichia coli in the presence of enrofloxacin. Vet. Microbiol., v.160, p.488-490, 2012. In Press.

COSTERTON, J.W.; STEWART, P.S.; GREENBERG, E.P. Bacterial biofilms: a common cause of persistent infections. Science, v.284, p.1318-1322, 1999.

DOGAN, B.; KLAESSIG, S.; RISHNIW, M. et al. Adherent and invasive Escherichia coli are associated with persistent bovine mastitis. Vet. Microbiol., v.116, p.270-282, 2006.

FERNANDES, J.B.; ZANARDO, L.G.; GALVAO, N.N. et al. Escherichia coli from clinical mastitis: serotypes and virulence factors. J. Vet. Diagn. Invest., v.23, p.1146-1152, 2011.

FLINT, S.; PALMER, J.; BREMER, P. et al. Biofilm Formation. In: Encyclopedia of Dairy Sciences. 2011, p.445-450.

FONTAINE, M.C.; SMITH, D.G. Microbial biofilms: does breaking the microbes' community spirit hold the key to beating persistent mastitis? Vet. J., v.171, p.387-388, 2006.

HILLERTON, J.E.; BERRY, E.A. Treating mastitis in the cow - a tradition or an archaism. J. Appl. Microbiol., v.98, p.1250-1255, 2005.

HOGAN, J.; LARRY SMITH, K. Coliform mastitis. Vet. Res., v.34, p.507-519, 2003.

HOIBY, N.; BJARNSHOLT, T.; GIVSKOV, M. et al. Antibiotic resistance of bacterial biofilms. Int. J. Antimicrob. Agents, v.35, p.322-332, 2010 .

LIPMAN, L.J.; DE NIJS, A.; GAASTRA, W. Isolation and identification of fimbriae and toxin production by Escherichia coli strains from cows with clinical mastitis. Vet. Microbiol., v.47, p.17, 1995.
LUCCHESI, E.G.; EGUCHI, S.Y.; MORAES, A.M. Influence of a triazine derivative-based biocide on microbial biofilms of cutting fluids in contact with different substrates. J. Ind. Microbiol. Biotechnol., v.39, p.743-748, 2012.

MELCHIOR, M.B.; VAARKAMP, H.; FINKGREMMELS, J. Biofilms: a role in recurrent mastitis infections? Vet. J., v.171, p.398-407, 2006.

MOREIRA, M.A.; OLIVEIRA, J.A.; TEIXEIRA, L.M.; MORAES, C.A. Detection of a chloramphenicol efflux system in Escherichia coli isolated from poultry carcass. Vet. Microbiol., v.109, p.75-81, 2005.

OLIVEIRA, M.; NUNES, S.F.; CARNEIRO, C. et al. Time course of biofilm formation by Staphylococcus aureus and Staphylococcus epidermidis mastitis isolates. Vet. Microbiol., v.124, p.187-191, 2007.

OLIVER, S.P.; PIGHETTI, G.M.; ALMEIDA, R.A. Mastitis Pathogens. Environmental Pathogens. 2.ed. Knoxville: Academic Press, 2011. 4170p.

PASSEY, S.; BRADLEY, A.; MELLOR, H. Escherichia coli isolated from bovine mastitis invade mammary cells by a modified endocytic pathway. Vet. Microbiol., v.130, p.151-164, 2008.

SCHWARZ, S.; KEHRENBERG, C.; WALSH, T.R. Use of antimicrobial agents in veterinary medicine and food animal production. Int. J. Antimicrob. Agents, v.17, p.431-437, 2011.

SHAFAHI, M.; VAFAI, K. Synthesis of biofilm resistance characteristics against antibiotics. Int. J. Heat Mass Transfer, v.53, p.2943-2950, 2010.

STEENEVELD, W.; VAN WERVEN, T.; BARKEMA, H.W.; HOGEVEEN, H. Cowspecific treatment of clinical mastitis: an economic approach. J. Dairy Sci., v.94, p.174188, 2011. 